As an essential part of the concept of 'Kaizen', the process of audit will itself be constantly subject to review. There will be changes in the issues it is most useful to consider, in methods, and in the way in which such discussions could influence clinical practice. It is important to regard the process as being largely experimental, and any attempt authoritatively to impose rules and procedures is likely to be based on a proper constructive understanding of the subject, and thus unlikely to serve the purposes behind this exercise.

\section{References}

BERWICK, D. M. (1989) Continuous improvement as an ideal in health care, New England Journal of Medicine, $320,53-56$.
JAQUES, E. (1955) Social systems as a defence against persecutory and depressive anxiety. In New Directions in Psycho-Analysis (eds M. Klein, P. Heimann, and R. E. Money-Kyrle) London: Tavistock Publications; paperback, Tavistock Publications, 1971.

MENZiEs LYTH, I. E. P. (1959) A case-study in the functioning of social systems as a defence against anxiety. A report on the nursing service of a general hospital. Human Relations, 13, 95-121.

- (1988) A psychoanalytic perspective on social institutions. In Melanie Klein Today (ed. E. Spillius) London: Routledge.

Plamping, D. (1991) The new NHS: Better to go forwards than backwards, Editorial British Medical Journal, 302, 737-738.

SMITH, R. (1990) Medicine's needs for Kaizen: putting quality first, Editorial, British Medical Journal, 301, 679-80.

\title{
Admission profile: towards community based services
}

\author{
R. S. Augustine, Consultant Psychiatrist and Psychiatric Tutor; P. N. KuRIAN, \\ Senior House Officer; and A. MichaEl, Senior House Officer, St Fintan's Hospital, \\ Portlaoise, Co. Laois, Republic of Ireland
}

This audit examined 65 consecutive admissions to a psychiatric hospital in the Irish Midlands over six months. The admissions came from a defined sector with a total population of 39,000 . In the year prior to the study major changes in the delivery of psychiatric care in the sector were instituted. These changes included the introduction of admission guidelines and extra resources in the community. The general practitioners who see mental illness at first contact were informed of these changes. Attempts were made by the sector psychiatrist team to screen for appropriateness of admission with regard to the special groups such as alcoholics, the aged and the mentally handicapped.

The extra resources for maintaining patients in the community were a new mental health centre (day hospital and day centre) and more out-patient clinics as well as hostel accommodation.

We felt that it was an appropriate time to examine the admission profile of patients admitted to the psychiatric hospital. The focus was on the sociodemographic and admission characteristics of patients who were admitted from this sector from January to June 1990.

\section{The study}

Patients were diagnosed by the auditing team according to ICD-9 classification. These diagnoses were

also used for the hospital in-patient reporting system for statistical purposes. We examined all the admissions over the months from 1 January 1990 to 30 June 1990.

A schedule was devised to look at selected sociodemographic characteristics and admission patterns as well as patient support systems. The source of support was taken to include the presence and availability of a relative or a key person as well as their appropriate concern for the patient's welfare. The level of support was rated according to the clinical judgement of the auditing team. An estimate of the general level of out-patient services during the same period was also carried out.

\section{Findings}

Sector population

Community services

Number of out-patients

Number of day hospital patients

Number of day centre patients

Number of general hospital consultations

Total

In-patient service

Number of patients admitted to the Acute Psychiatric Unit

$$
=39,000
$$$$
=256
$$$$
=175
$$$$
=70
$$$$
=27
$$$$
=528
$$

$=65$ 


\section{The significant socio-demographic features}

Of the total number of patients admitted, $6 \%$ were more than 65 years old. In the total sample of patients studied there were twice as many males as females. More than half of the patients $(52 \%)$ were single. The auditing team rated $78 \%$ of the patients as receiving moderate to good support from the family. This was particularly true with regard to the schizophrenia group (94\%). Most of the patients $(84 \%)$ were unemployed and were in receipt of appropriate social welfare allowances. This was true for all diagnostic groups except for those with alcohol dependence, more than half $(63 \%)$ of whom were employed. Only $5 \%$ of patients lived in rented accomodation. The rest lived either in their own homes $(55 \%)$ or shared their family home (40\%).

\section{Admission characteristics}

Table I shows the gender distribution in the diagnostic groups. The length of stay in each diagnostic group is depicted in Table II. Sixty-five patients accounted for 80 admissions. The reasons for admission were:

Relapse of psychiatric symptoms (not related to alcohol)

$41 \%$

Assessment

Crisis intervention

Deliberate self harm

Alcoholism

TABLE I

Diagnostic groups and gender distribution

\begin{tabular}{lrrr}
\hline & $M$ & $F$ & Total \\
\hline Alcohol dependence & 11 & 2 & 13 \\
Schizophrenia & 10 & 7 & 17 \\
Affective disorder & 7 & 4 & 11 \\
Neurosis disorder & 2 & 10 & 12 \\
Personality disorder & 6 & 1 & 7 \\
Others & 5 & 0 & 5 \\
\hline
\end{tabular}

TABLE II

Diagnostic groups and length of stay

\begin{tabular}{lc}
\hline & $\begin{array}{c}\text { Mean duration } \\
\text { of stay in days }\end{array}$ \\
\hline Alcohol dependence & 13.9 \\
Schizophrenia & 21.7 \\
Affective disorder & 22.7 \\
Neurotic disorder & 20.2 \\
Personality disorder & 13.7 \\
Others: & \\
$\quad$ Mental handicap & \\
Organic brain syndrome & \\
Epileptic psychosis & 68.6 \\
\cline { 2 - 2 } Total (average length of stay) of all groups & 26.8 \\
\hline
\end{tabular}

Less than half the patients $(45 \%)$ had been screened by the psychiatric team prior to the arrival at the psychiatric hospital for admission.

Among those patients diagnosed as having alcohol dependence syndrome, $70 \%$ were referred by the GP directly to the acute admission unit of the psychiatric hospital.

Our audit set out to examine the characteristics of the patients who still use the in-patient services since the introduction of increased community support services. The patients come from a stable essentially homogenous rural population. This probably accounted for the high level of family support we perceived. The good level of accommodation and welfare support are indicative of this caring society. We were disappointed with the low level of utilisation of community services prior to admission though we accept that the patients were appropriately admitted.

This audit helped us identify the current consumer population. Further studies will shed light on the special needs of these subgroups and how best the organisation can meet those needs.

\section{Acknowledgement}

We thank Dr L. K. Hanniffy, Resident Medical Superintendent/Chief Psychiatrist, St Fintan's Hospital, Portlaoise for permitting us to publish this audit. 